\title{
Chronic total occlusions (CTO) in the field of Percutaneous Coronary interventions (PCI) is a challenge- the result of initial 25 cases.
}

\author{
MIR Jamaal Uddin, M. Ali, Kh.Q Islam, AHK Chowdhury, M.A.Salam, \\ M.F. Rahman, M. Atabar Ali, M. Raisuddin, M. Saiful Islam, \\ M. Shahabuddin, M. Shamim, M. Islam, N. Islam, H.P. Nepal
}

With an aim to investigate the success rate \& immediate clinical outcome of Percutaneous Coronary intervention (PCI) for chronic total occlusion (CTO). we analyzed $\mathrm{PCl}$ of 150 cases. This is an on going study started from April 2002 to till date. The technique of $\mathrm{PCl}$ involving CTO has improved over time. However limited data on acute \& follow up result in patients treated with $\mathrm{PCI}$ on $\mathrm{CTO}$ in recent years are available. Our of 150 cases of $\mathrm{PCl}, 25$ patients were of CTO of $>30$ days of duration. The result of their $\mathrm{PCl}$ were evaluated. The age range of the Pts were $50 \pm 10 \mathrm{yr}$; with male female ratio of 5:1 Diagnosis of the Pts were old myocardial infarction with Post MI angina 20 cases, Chronic stable angina 5 cases. Single vessel disease was 20 cases \& Double vessel disease was 5 cases. Angiographic success rate was 20 cases (80\%), Procedural success 19 cases (76\%), Clinical success 18 cases (70\%). Failed PCl in 5 cases, these were very much calcified lesions. In one case standard wire was passed but balloon could not be negotiated. Successful PCI was achieved in a high percentage of CTO with a low incidence of complications. 